\title{
A conquista do direito das crianças à educação: da proposição à materialização
}

\author{
Conquering the children's right to education: \\ from proposition to materialization \\ Conquistar el derecho a la educación del niño: \\ de la propuesta a la materialización
}

PRISCILA KELIDA ASSIS GALVÃO

Orcid ld: https://orcid.org/0000-0002-0696-368X Instituto Federal de Educação, Ciência e Tecnologia de Goiás

TELMA APARECIDA TELES MARTINS SILVEIRA

Orcid Id: https://orcid.org/0000-0003-1135-1087

Instituto Federal de Educação, Ciência e Tecnologia de Goiás

IVONE GARCIA BARBOSA

Orcid Id: https://orcid.org/0000-0002-0636-8485

Universidade de São Paulo

\begin{abstract}
Resumo: O presente artigo analisa o processo histórico de consolidação do direito à Educação Infantil no Brasil, buscando perceber os condicionantes sociais e políticos na elaboração da Carta Magna de 1988. Utilizamos o materialismo histórico-dialético, apreendendo em sua concretude social e histórica os múltiplos condicionantes implicados no processo. Realizamos um levantamento bibliográfico e documental acerca do período da Constituinte 1985-1988. As evidências anunciam a contradição dos diferentes grupos na constituição das políticas públicas e a busca de consolidação do direito à educação.
\end{abstract}

Palavras-chave: Educação Infantil; Direito da criança; Políticas Públicas.

\begin{abstract}
This article analyzes the historical process of consolidating the right to Early Childhood Education in Brazil, seeking to understand the social and political conditions in the elaboration of the 1988 Magna Carta. We used historical-dialectical materialism, apprehending in its social and historical concreteness the multiple conditions involved in the process. We carried out a bibliographical and documentary survey about the 1985-1988 Constituent period. The evidence announces the contradiction of different groups in the constitution of public policies and the search for the consolidation of the right to education.
\end{abstract}

Keywords: Early childhood education; Children's rights; Public policy. 
Resumen: El articulo analiza el proceso histórico de consolidación del derecho a la Educación Infantil en Brasil, buscando comprender las condiciones sociales y politicas en la elaboración de la Carta Magna de 1988. Realizamos un levantamiento bibliográfico y documental sobre el periodo Constituyente 1985-1988. La evidencia anuncia la contradicción de diferentes grupos en la constitución de políticas públicas y la búsqueda de la consolidación del derecho a la educación.

Palabras clave: Educación de la primera infancia; Derechos de los niños; Politicas públicas.

\section{INTRODUÇÃO}

A educação da criança, do zero até seis anos de idade ${ }^{1}$, passou a ser reconhecida pela Constituição Federal (CF) de 1988 (BRASIL, 1988), pelo Estatuto da Criança e do Adolescente (ECA), de 1990 (BRASIL, 1990), e pela Lei de Diretrizes e Bases da Educação Nacional (LDB) de 1996 (BRASIL, 1996) - dentre outros documentos legais - como direito da criança e de suas famílias. O reconhecimento do direito à educação nessa faixa etária da vida no Brasil está implicado a movimentos políticos, sociais e econômicos que se desdobraram entre as décadas de 1970 e 1980, anos finais da Ditadura Militar. Marco da consolidação da "nova república" (IANNI, 1985) do país que envolveram distintos grupos sociais e políticos na elaboração da Constituição Federal de 1988. No contexto de debate e mobilizações populares em torno da democratização da sociedade, a legislação incorporou concepções balizadas na ideia de cidadania e direitos, considerando a Educação Infantil como um dos direitos das crianças e dever do Estado.

O presente artigo objetivou analisar o processo histórico de consolidação do direito da criança de zero até seis anos de idade à educação no Brasil, buscando perceberos condicionantes históricos, sociais, e políticos no período da Constituinte 1985-1988 e as diferentes contribuições da sociedade civil na elaboração da Carta Magna de 1988, o que possibilitou, em seu processo contraditório, a efetivação de leis que demarcaram os direitos sociais das crianças brasileiras, dente eles a educação. Desse modo, utilizamos como referencial teórico-metodológico o materialismo histórico-dialético, que implica em compreender esse momento

1 A Educação Infantil foi alterada pela Emenda Constitucional no 53/2006, que ampliou o Ensino Fundamental de oito para nove anos, reduzindo a Educação Infantil de zero a cinco anos de idade. Porém, nesse trabalho, optou-se por manter a expressão "zero a seis anos de idade" por dois motivos: primeiro, por demarcar uma posição na defesa da garantia do direito das crianças que completarem seis anos após o ponto de corte de 31/3, conforme Resolução CNE/CEB n 1, de 14 de janeiro de 2010, permanecerem na Educação Infantil no ano corrente. Esse posicionamento está demarcado em documentos do Movimento de Interfóruns no Brasil (MIEIB). Em segundo lugar, por acreditar que os processos de aprendizagem e desenvolvimento estão para além de uma delimitação etária. Em nossa perspectiva teórico-metodológica, a prática pedagógica, situada em um contexto social, cultural, econômico e político, deve estar alicerçada e organizada, tendo por referência as especificidades concretas de desenvolvimento das crianças. 
histórico em suas contradições, seu caráter de totalidade e de provisoriedade que possibilita uma análise articulada das informações arregimentadas, abrangendo em seus múltiplos determinantes (MARX, 1983). Para tanto, realizamos uma pesquisa de cunho documental e bibliográfica, a fim de compreender as questões postas no campo da Educação Infantil para serem debatidas ante a realidade que se vivencia e tem provocado novos redimensionamentos acerca de sua identidade.

Sendo assim, o artigo estrutura-se em duas partes interligadas. Primeiro remete-se a análise da conquista dos direitos humanos como movimento histórico, político e social, bem como, a mobilização, articulação e participação da sociedade civil na garantia dos direitos sociais das crianças brasileiras. Em um segundo momento, analisaram-se o processo da Constituinte (1985-1988), os discursos e as propostas construídas pelo reconhecimento da Educação Infantil como direito.

\section{A EDUCAÇÃO DA CRIANÇA NA CONSTITUIÇÃO FEDERAL DE 1988: O PAPEL DOS MOVIMENTOS SOCIAIS}

O direito é uma construção social. Contudo não existem direitos fundamentais por natureza ou direitos naturais, pois eles são construídos historicamente, em processos contraditórios e imanentes da condição humana. De acordo com Bobbio (2004) os direitos não existem enquanto seres absolutos, mas se constituem nas relações entre os homens, de acordo com o contexto social e político de uma dada época. O que parece ser importante e fundamental numa dada época e civilização pode não ser em outras culturas e em outros tempos históricos. O que rege então a constituição do direito, em um movimento de lutas, tensões e contradições, são as necessidades formadas naquele momento aos sujeitos que a vivenciam, pois há uma incessante busca pela garantia do direito de se expressar, ver e de compreender o mundo.

A análise das questões pertinentes aos direitos humanos deve ser compreendida em uma dada realidade, com seus problemas históricos, sociais, políticos e econômicos que estão intrínsecos à sua efetivação (MARX; ENGELS, s/d). Os direitos sociais são fundamentais em uma sociedade capitalista pautada pela desigualdade entre os sujeitos. Eles se materializam na luta cotidiana, nos embates das classes sociais antagônicas, se configurando como "[...] conquistas que se dão nas práticas sociais, construídas e reconstruídas nas lutas, nas negociações, nos embates e debates entre os diferentes grupos sociais e não como um presente que emana do Estado" (BARBOSA, 2001, p. 05). 
Com isso, as ações do Estado, no que se refere às políticas sociais, se articulam às demandas ensejadas pela classe trabalhadora e, ao mesmo tempo, visam a atender aos interesses capitalistas de acumulação de capital (MANACORDA, 1991). Os interesses antagônicos se confrontam na realidade social, tendo o Estado de buscar o consenso, mas sempre mantendo o interesse da classe dominante (SANFELICE, 2003; FRIGOTTO; CIAVATTA, 2003).

Distintas declarações foram construídas em vários lugares do mundo para resguardar os direitos comuns dos cidadãos, dentre elas, a Declaração Universal dos Direitos da criança. Mas, um dos grandes problemas é fazer com que esses direitos sejam respeitados por todos (CAMPOS, 1999; BARBOSA, 2001). Percebe-se que, nessa realidade material, muitas coisas ainda estão por ser construídas na luta pela garantia das condições já acordadas e ainda não saíram do papel.

A Constituição Federal (BRASIL, 1988) pode ser destacada como um marco importante para o Brasil, em meio a debates e embates com a participação de todos os setores organizados da sociedade civil, em que se consagrou ao povo brasileiro, direitos sociais ignorados por um longo período, sendo denominada de "Constituição Cidadã" pelo presidente da Constituinte Ulisses Guimarães. Também considerada por muitos como cidadã porque incorporou sujeitos que historicamente foram alijados dos direitos sociais a uma vida digna, como educação, saúde, lazer, habitação, segurança, dentre outros. O direito à educação demarca, por exemplo, que todos os cidadãos deverão ser tratados como iguais nas condições de acesso e permanência nas instituições educacionais que devem ser para todos.

Os movimentos sociais se inserem nesse cenário de lutas e garantias de direitos, pois têm um papel importante na constituição e definição de políticas públicas para a sociedade em moção de tensionamento da realidade na garantia dos direitos sociais. Os movimentos sociais se caracterizam pela ação contestatória à exploração e dominação que emergem de uma sociedade dividida entre classes e grupos sociais com interesses distintos (MARX, 1983).

Importa destacar que os movimentos sociais “[...] não são homogêneos, nem do ponto de vista de sua composição, nem de suas demandas [...]" (GALVÃO, 2011, p. 113). Desse modo, na busca pela superação das desigualdades, de diferentes graus de intensidade, tensionam o Estado à construção de políticas públicas a fim de garantir na legislação os direitos sociais daqueles que foram historicamente colocados à margem, como, por exemplo, a infância e seu direito à educação. Assim, as ações dos movimentos sociais não podem ser compreendidas de modo 
isolado, faz-se necessário reconhecer o seu caráter político-social, reconhecido por Gohn (2000) como redes de articulações que possibilitam tensionar a realidade concreta em seus aspectos políticos, econômicos e sociais.

A década de 1980 no Brasil foi profícua para a constituição sólida dos movimentos sociais, que se ressignificavam e ganhavam força na luta pelos direitos sociais, pela constituição de um Estado de direitos políticos e sociais, opositores claros de um Estado ditatorial (BRZEZINSKI, 2013). Nesse contexto, ampliaram-se consideravelmente debates e mobilizações sociais em torno da democracia e da garantia de direitos dos cidadãos brasileiros, dentre os quais a educação das crianças com idade entre zero a seis anos (BARBOSA; ALVES; MARTINS, 2008). Desse prisma, buscamos analisar a inserção da Educação Infantil no âmbito da Constituição Federal sancionada em 1988.

A criação da Assembleia Nacional Constituinte - ANC (1985-1988) marcou historicamente, o período de transição para a democracia política que estava se instaurando no país. Sua efetivação se deu em um processo contraditório, com projetos sociais em disputa em que expressam várias ambiguidades e conflitos. O regimento da nova Constituição envolveu a participação social, por meio de propostas de movimentos populares, alavancadas após a década de 1970 pelas organizações civis, bem como pela proposição de organismos internacionais (VIANNA, 2008). A constituição da Assembleia Constituinte, portanto, conflui projetos em diferentes perspectivas e concepções que contribuem para a compreensão do contexto social, político e econômico em que se insere e constitui-se arena de disputas de projetos de sociedade distintos.

Antes do início das atividades regimentais da ANC (1987-1988) já haviam pensadores da educação se organizando politicamente, em destaque a IV Conferência Brasileira de Educação realizada em setembro de 1986 na cidade de Goiânia, capital do estado de Goiás, atribuindo educação como direito de todos os cidadãos brasileiros, incluída a oferta da Educação Infantil como dever do Estado (MARTINS, 2018). Assim, a Carta de Goiânia redigida pelos educadores presentes na conferência se constitui em “[...] uma peça que tinha múltiplas características de análise da conjuntura educacional no momento pré-constituinte, manifesto técnico-político com a indicação de itens que deveriam constar da Nova Constituição e peça de mobilização dos atores educacionais" (MARTINS, 2018, p. 144).

Campos (1986) e Rosemberg (2008) destacam que os movimentos sociais pressionaram, pela intensa mobilização política, para que entrasse na agenda da Constituinte (1985-1988) a discussão dos direitos das crianças. Desse movimento surgiram duas frentes de campanhas, "Criança Prioridade Nacional" e "Criança 
e Constituinte", "que originaram duas emendas populares, que se integraram e foram apresentadas ao Congresso Nacional Constituinte" (ROSEMBERG, 2008, p. 309).

A ocasião da Constituinte foi um grande momento de articulação do movimento de defesa dos direitos das crianças e adolescentes. Envolvendo a participação da Comissão Nacional Criança e Constituinte, a qual marcou o período de construção da nova Carta Constitucional (BRASIL, 1988). Participou ativamente do processo da ANC (1985-1988) apresentando propostas e realizando discussões sobre a educação contando com a presença de diversas entidades representativas. Realizou assim, um amplo processo de sensibilização, conscientização e mobilização da opinião pública e dos constituintes. Encontros Nacionais, debates em diversos Estados, eventos com milhares de crianças em frente ao Congresso Nacional, panfletagem e abordagem pessoal dos parlamentares constituintes, participação nas Audiências Públicas, carta de reivindicações com mais de 1,4 bilhões de assinaturas de crianças e adolescentes, exigindo a introdução dos seus direitos na nova Carta Constitucional (GOMES DA COSTA, 1993).

Os movimentos sociais integrados e organizados na Comissão Nacional Criança e Constituinte tiveram como integrantes Organizações governamentais e não governamentais e entidades representativas da sociedade, como o Conselho Nacional dos Direitos da Mulher, a Federação Nacional de Jornalistas, Conferência Nacional dos Bispos do Brasil (CNBB), Ordem dos Advogados do Brasil (OAB), o Movimento Nacional Meninos e Meninas de Rua, a Organização Mundial Para Educação Pré-Escolar (OMEP) e o Fundo Internacional de Emergência das Nações Unidas para a Infância (UNICEF). Fizeram parte também os Ministérios da Educação, do Planejamento, da Cultura, da Justiça, do Trabalho, da Saúde, da Previdência e Assistência Social.

A campanha "Criança e Constituinte" foi um amplo movimento que aglutinou mais de trezentas entidades ligadas à defesa dos direitos da criança. Em cada estado da Federação havia uma Comissão Estadual da Criança e Constituinte. Foram realizadas sessões e discussões de estudos e dois encontros nacionais para debater e aprovar as propostas da Constituinte. Essa ampla mobilização repercutiu formas de conscientização e pressão para garantir a construção e aprovação do que se conhece hoje como CF (BRASIL, 1988). Esse movimento em prol das crianças contou também com a participação delas em diferentes atos pelo país, conforme explicita Didonet (1992, p. 26-7):

Nas escolas, elas estudavam e debatiam sobre seus direitos e sobre os problemas 
reais que estavam enfrentando. Nas ruas, elas iam em busca de assinaturas de outras crianças e de adultos em apoio às reivindicações que seriam encaminhadas à Assembléia Nacional Constituinte. Nas praças, elas realizavam dias de mobilização, de desenho sobre seus direitos. Em assembleias legislativas e câmara de vereadores, realizavam simulações de sessões nas quais debatiam suas questões, com a assistência de deputados e vereadores. Marchas e passeatas, concursos de redação e de desenho, cartas aos constituintes, participação em programas de rádio e de televisão, foram outras formas que as crianças utilizaram para expressar como desejavam que a sociedade as visse e com elas se relacionasse.

O movimento "Criança e Constituinte" se debruçou sobre o direito da educação às crianças de zero a seis anos de idade. Estava presente nos discursos dos movimentos sociais o termo cidadania ou cidadão. Essa valorização do direito à educação das crianças na Constituição Federal de 1988 significou “[...] acesso à educação pública, gratuita que deve incluir todos os brasileiros. [...]também, a universalização do acesso, a ampliação da jornada escolar ancorada na concepção integral e a garantia da permanência bem sucedida [...]" (BRZEZINSKI, 2013, p. 234). Dentre as conquistas, destaca-se o direito ao atendimento em creches e pré-escolas, caracterizadas na Carta Constitucional no artigo 208 inciso IV como "instituições educacionais".

Em um documento intitulado "Comissão de creche - Creche e Constituinte" vê-se uma gama de argumentos sobre a creche e a pré-escola e como deveriam ser reguladas na Constituição Federal. Nesse documento pode-se destacar a inserção da creche em um processo de luta pela sua inserção.

A questão da creche está ligada tanto a educação em geral, como a condição da mulher. Assim, se pensarmos que a Constituição geralmente se divide em capítulos que tratam dos vários temas que essa lei deve contemplar, talvez devêssemos prever que a menção à creche deveria constar duas vezes: uma na parte referente à educação e outra na parte referente à família ou à mulher (COMISSÃO DE CRECHE - CRECHE E CONSTITUINTE, s/d, p. 3).

Diante do exposto, destaca-se a justificativa para a forma como a educação da criança do nascimento aos seis anos de idade se circunscreve na CF (BRASIL, 1988) no artigo 208: “O dever do Estado com a educação será efetivado mediante a garantia de: IV - atendimento em creche e pré-escola às crianças de 0 a 6 anos de idade". Manteve-se a sobreposição do atendimento que, historicamente, fez parte da educação da criança, ao mesmo tempo, garantiu o direito das crianças de zero até três anos de idade de serem identificadas, de forma explícita, posteriormente, na LDB (BRASIL, 1996). O documento explicita a busca de garantias para a efetivação desse direito na carta Magna, pois havia a possibilidade de a creche não ser inclusa no âmbito educacional. 
A defesa da creche no documento "Comissão de creche - Creche e Constituinte", também consubstanciada na perspectiva do direito, atribui que é direito da mulher optar por esse atendimento, independente de trabalhar ou não. A luta pela creche estava mais próxima, mais clara e mais consistente para o movimento de mulheres do que para os educadores. O movimento de mulheres, na busca por assegurar o direito da mulher à igualdade de condições no exercício de sua cidadania e de seu direito ao trabalho, visava a garantir também, no âmbito da CF (BRASIL, 1988), formas alternativas de guarda e educação das crianças de zero até seis anos de idade. A assunção da Educação Infantil na Constituição (BRASIL, 1988) não era um desejo e prerrogativa de todos da área educacional. Desse modo, naquele cenário, o documento da referida Comissão indicava que seria melhor assumir o risco de manter a expressão creche do que introduzir um novo formato que concretamente não passaria,

Esperamos que a questão da creche- seja incluída na Constituição através da pressão dos grupos de mulheres, pois no meio educacional ainda não, existe clima favorável para isto; se a proposta fosse definida para a faixa de 0 a 6 anos, provavelmente não passaria (COMISSÃO DE CRECHE - CRECHE E CONSTITUINTE, s/d, p. 8).

De acordo com o exposto, percebe-se um ponto de controvérsia entre os educadores, porque os argumentos se fazem em diferentes ordens, como a extensão da oferta de vagas na quantidade necessária para o cumprimento da obrigatoriedade do Ensino Fundamental, que implica em o Estado ofertar e a criança frequentar. Ao colocar mais uma etapa educacional, as verbas poderiam ser divididas e não se conseguiria expandir, da forma como deveria, o ensino obrigatório. De acordo com Rosemberg (1989), a Anped assumiu a defesa da pré-escola no sistema de ensino, mas não da criança de zero a três anos de idade à creche. Também como outras associações e mobilizações sociais, buscaram apresentar outras saídas, como “[...] extensão da licença maternidade, ou ampliação do salário do pai para que a mãe cuidasse dos filhos” (ROSEMBERG,1989, p. 93) a fim de resguardar o atendimento via assistência e saúde, mas não educacional.

A defesa dos movimentos de mulheres e de um grupo em defesa das crianças e adolescentes, não era a obrigatoriedade da expansão e frequência da criança à creche, mas o que se reivindicava era "[...] a obrigação do Estado na oferta, como contrapartida do direito da criança. "[...] A creche deve existir enquanto uma possibilidade para as famílias, mas ninguém, evidentemente, obrigará nenhuma mãe a optar por essa alternativa" (CAMPOS, 1986, p. 59). Desse modo, buscava-se ressaltar a creche como direito da criança e não só da mulher. Isso implicava na mudança do olhar, em que a responsabilidade da 
educação das crianças do nascimento aos seis anos de idade não era somente da mulher e da família, mas também do Estado, este com a responsabilidade e o dever de oferecer atendimento com qualidade a todas as crianças.

Sobre a questão da dotação orçamentária, outro ponto foi destaque para a educação da criança de zero até seis anos de idade, que deveriam ser incluídas aos recursos financeiros, porém havia um movimento para a Emenda Calmon ${ }^{2}$ que efetivamente aumentou os recursos para a área da educação. Contudo, essa Emenda tratava somente da pré-escola, e a creche ficaria de fora, naquele momento, não havia condições de se realizar um debate mais aprofundado. Isso fez esbarrar numa problemática, considerar a creche como uma modalidade de ensino, pois seria necessário "[...] discutir as condições que a creche teria de disputar as mesmas verbas que devem cobrir outros níveis de ensino, com lobbies mais poderosos - como seria o caso dos cursos superiores - ou com maior legitimidade na área educacional" (CAMPOS, 1986, p. 60).

Assim, o movimento de consolidação do direito da criança à educação desde o seu nascimento se deu em um processo de negociação com perdas e ganhos. O debate em torno da Educação Infantil se dava como direito associado ao trabalho de mães e pais, ou como superação do fracasso escolar, também á educação, com necessidade de profissionais com formação e atuação adequada às idades das crianças (CAMPOS, 1986; ROSEMBERG, 2008).

A definição no período da Constituinte (1985-1988) em manter o termo creche e pré-escola significava, naquele momento, uma referência ao que a sociedade conhecia como espaço de atendimento às crianças pequenas enquanto seus pais trabalhavam, sendo garantido na CF (BRASIL, 1988), o que antes nunca esteve explícito em nenhuma legislação, conforme já apontado. A manutenção ao termo significou para a população a clareza do que estava sendo defendido, e era objeto das lutas dos movimentos sociais. Mas, de modo contraditório ao reforçar a importância da creche como espaço educacional, a manutenção do termo ocasionou também a manutenção da visão assistencialista, verticalizando agora para as crianças menores de três anos de idade, permitindo um atendimento que tenha como referência marcante o cuidar, dissociado do educar. Faz-se necessário uma organização social e política para discutir os princípios que norteiam o

2 Foi uma Emenda Constitucional apresentada por João de Medeiros Calmon ao Congresso Nacional, em que se destinavam percentuais fixos de investimento para a educação. A União deveria destinar $18 \%$, e os estados e municípios $25 \%$. Ela passou a ser chamada pelo seu sobrenome. Essa proposição passou posteriormente a ser aperfeiçoada. Importa destacar que a referida Emenda Calmon, ao final de 1983, levou a uma discussão acirrada sobre a sua aplicabilidade da distribuição de recursos. Essa emenda constitucional se baseou na Constituição Federal de 1946 e foi parcialmente incorporada na Lei de Diretrizes e Bases da Educação Nacional (Lei n. ${ }^{\circ}$ 4.024, de 20 de dezembro de 1961), em que trata da manutenção e do desenvolvimento do ensino (GOMES, 1989). Para saber mais, ver Gomes (1989), que descreve todo o processo histórico do Brasil pela garantia do financiamento da educação brasileira. 
atendimento educacional às crianças, desde o nascimento até três anos de idade, e sua relação indissociável com o trabalho desenvolvido com as crianças de quatro até seis anos de idade.

Num movimento contraditório, a Constituição Federal (BRASIL, 1988) rompeu, no âmbito da Lei, com a ideia de assistencialismo e amparo, mas na realidade concreta, o que ainda permanece tem relação com a própria origem da creche, em que a associação creche/criança está ligada diretamente à assistência/ pobreza, mantendo ainda um caráter excludente. Diante desse cenário, considerase hoje um retrocesso à segmentação do atendimento da Educação Infantil em creches e pré-escolas que, na década de 1980, pareceu tão importante para a construção de outro olhar para a educação. A ideia de que a creche era espaço de guarda, poderia oferecer o aspecto educacional, bem como a pré-escola era o lugar de educação que poderia oferecer a guarda foi assumida pelos intelectuais da área da educação da criança (CAMPOS, 1979).

$\mathrm{Na}$ década de 1980, a pesquisa realizada por Rossetti-Ferreira (1984) mostrava a necessidade de se opor à creche como "mal necessário". A autora destacou a importância do desenvolvimento da criança em espaços coletivos, se opondo à ideia construída de que a figura da mãe no processo educativo, formativo da criança, era imprescindível. E que as crianças que ficavam em espaços coletivos, privadas do convívio constante da mãe, tinham sérios prejuízos; então só seria utilizado esse serviço para mães que de fato eram obrigadas a trabalhar. Essa pesquisa repercutiu positivamente, pois relativizou a ideia negativa em relação ao atendimento da criança em creche. Defendeu-se a creche no âmbito educacional e visou-se à difusão da compreensão de que as crianças pequenas poderiam estar com outros adultos além da mãe, não ocasionando prejuízo ao seu desenvolvimento socioafetivo; outros adultos poderiam estabelecer laços afetivos estáveis com as crianças.

Essa mudança de olhar acerca da creche, de "mal necessário" à ideia de direito, pelo menos no âmbito legal/jurídico, implicou em legitimá-la como instituição educativa, direito das crianças e de suas famílias, e não mais como um equipamento restrito às mães que trabalhavam. Os cidadãos agora têm o direito de usufruírem de espaços coletivos para o cuidado e a educação de seus filhos. 


\section{A MATERIALIZAÇÃO DO DIREITO À EDUCAÇÃO INFANTIL NA CONSTITUIÇÃO FEDERAL DE 1988: UMA ANÁLISE DA CONSTITUINTE}

A Constituição Federal de 1988 (BRASIL, 1988) reconhece a criança como sujeito de direitos. A ênfase a essa conquista se refere a ser a primeira Constituição Federal Brasileira a incluir as crianças de zero a seis anos de idade sob amplos direitos sociais (COELHO, 1998). Tornando assim a Constituição mais expressiva na trajetória histórica brasileira.

No entremeio de medidas de desregulamentação dos Atos Institucionais imputados no período ditatorial (1964-1985), marca-se o fim da Ditadura Militar em 1985. Esse momento histórico, em movimentos de debates e embates e de lutas sociais por direitos, desencadeou o processo de redemocratização do país e a necessidade de formulação de uma Nova Constituição brasileira que foi oficializada em 1988. A CF (BRASIL, 1988) expressa a correlação de forças no campo da política brasileira. Desse modo, sua elaboração data da instituição da Assembleia Nacional Constituinte-ANC, consolidada em formato de congresso pela Emenda Constitucional no 26, de 27 de novembro de 1985, obteve diversas colaborações de grupos políticos e sociais, públicos e privados, em um processo de luta de forças antagônicas, pensando e elaborando propostas, a fim de delimitar os direitos civis em todas as áreas sociais.

O trabalho da Constituinte perdurou desde $1^{\circ}$ de fevereiro de 1987 até 5 de outubro de 1988, sendo direcionada pelo deputado federal do PMDB de São Paulo, Ulysses Guimarães, eleito presidente da ANC pelos parlamentares constituintes, contabilizando 487 deputados federais e 49 senadores (OLIVEIRA, 1993). A sistematização da Assembleia Nacional Constituinte (1985-1988) ocorreu em 7 etapas, em um primeiro momento se deu a estrutura do regimento interno da ANC (1985-1988), logo foram instaladas 8 comissões (numeradas de I-VIII), subsequente a criação de 24 subcomissões (três subcomissões para cada comissão), por fim a Comissão de sistematização (OLIVEIRA, 1993). A Comissão de Sistematização destinava-se à elaboração do texto final da Carta Constituinte, submetida as demais etapas da elaboração.

Pela conjuntura histórica sobre a participação da família, específico as mães, e educadores em defesa de uma concepção de educação para todos, delimitamos nossas análises nas proposições de constituintes e cidadãos que participaram da VIII Comissão intitulada Comissão da Família, da Educação, Cultura e Esportes, da Ciência e Tecnologia e Comunicação. Com ênfase nas propostas destinadas à Subcomissão da Educação, Cultura e Esportes - VIIIa, e a Subcomissão da Família, Menor e Idoso - VIIIc. 
O processo de construção da Constituição Federal de 1988 contou com a participação de diversas entidades e instituições entre elas os movimentos sociais, grupos privados e estudiosos da educação envolvendo representações do Poder Público, assim como entidades relacionadas aos movimentos sociais (ROSEMBERG, 2008; MARTINS, 2018). A efetivação desse documento mandatório foi marcada por muitos encontros, discussões e proposições, consolidando, não sem contradições, o reconhecimento das crianças de zero a seis anos, como sujeitos de direitos.

Importa destacar que não é por generosidade dos poderosos que a criança se torna digna de direitos sociais, dentre os quais, uma educação cidadã. Nesse processo, a correlação de forças que determina a formulação de políticas públicas não é apenas local, mas apresenta componentes da organização mundial, no contexto crescente de globalização e mundialização do capital que impõe uma esfera de poder transnacional (IANNI, 1997). Há uma pressão social dos movimentos e grupos sociais, bem como dos organismos multilaterais com projetos de sociedades diferentes, que tensionam e evidenciam o próprio desenvolvimento desigual e combinado do modo de produção capitalista, “[...] explorando o trabalho de adultos e de crianças e que paradoxalmente impõe a necessidade de criação de mecanismos de proteção daqueles que são explorados" (BARBOSA, ALVES, MARTINS, 2008, p. 11).

Destacamos a segunda parte da $22^{\circ}$ reunião extraordinária da Subcomissão da Educação, Cultura e Esportes - VIIIa houve a participação da Comissão Nacional Criança e Constituinte, representado por seu coordenador Vital Didonet. A Comissão apresenta, dentre suas propostas que “[...]o Estado garantirá gratuitamente às famílias que desejarem a educação e assistência às crianças de 0 a 6 anos, em instituições específicas, como 48 creches e préescolas" (ASSEMBLEIA NACIONAL CONSTITUINTE, SUBCOMISSÃO DA EDUCAÇÃO, CULTURA E ESPORTES, 1987, p. 391). Essa presença da delimitação do espaço educativo vinculada à educação vem de um longo movimento de defesa pelos direitos das crianças e mulheres brasileiras que tem nos movimentos sociais dessas entidades sua referência fundamental.

A justificativas apresentadas remetem a necessidades das famílias, à imersão da mulher no mercado de trabalho, como também a estudos científicos que comprovam a infância como fase essencial para o desenvolvimento. $O$ constituinte Louremberg Nunes Rocha questionou Vital Didonet sobre a oferta da creche e pré-escola como possibilidade de ser organizada por entidades, grupos específicos, vinculadas ao âmbito assistencialista e não da educação. Vital Didonet rebateu, afirmando a necessidade de compreensão da educação desde o nascimento como direito da criança brasileira e ressaltando a concepção de que 
a criança é cidadã e sujeito de direitos, o que engloba diversos ministérios para pensar o atendimento de modo integrado e interligado assim "[...]foi discutido como um direito da criança à vida, ao desenvolvimento, a ser cidadã participante da sociedade. A educação aparece, porque é decisiva, é importante, como também aparece em outros setores" (ASSEMBLEIA NACIONAL CONSTITUINTE, SUBCOMISSÃO DA EDUCAÇÃO, CULTURA E ESPORTES, 1987, p. 395).

$\mathrm{Na} 11^{\circ}$ reunião da Subcomissão da Família, do Menor e do Idoso, receberam a participação de representações do Conselho Nacional dos Direitos da Mulher, também a participação da professora Fúlvia Rosemberg representando a Fundação Carlos Chagas. Como ressalta a defesa da representante do Conselho Nacional dos Direitos da mulher, a Educação Infantil se constitui como direito da criança, necessitando ser estruturada de forma profissionalizante, subsidiada pelo Estado, envolvendo o cuidar e educar, como indissociáveis, princípio amplamente defendido na Educação Infantil, considerando as especificidades das crianças. Houve também a participação da representante da Secretaria do Menor do Estado de São Paulo explanando sobre a regulamentação do trabalho infantil interligada a caráter educativo, como medida preventiva da marginalização.

Observa-se que toda a mobilização dos movimentos sociais em defesa da criança se fez presente nos embates e debates acerca dos direitos sociais. Assim, identifica-se nos discursos apresentados, a defesa dos direitos das crianças brasileiras à Educação Infantil, porquanto desencadeiam um novo olhar para a oferta da educação, possibilitando assim ampliar a responsabilidade para o âmbito educacional, que antes era predominante da família para também a sociedade e o poder público (CAMPOS, 1989).

Pelo reconhecimento da criança do nascimento aos seis anos de idade pelo Estado possibilitou manifestações de diversas "formas de ação concepções e significados atribuídos à infância, às crianças e sua educação, à instituição e ao trabalho docente, refletindo-se na construção da identidade dos seus profissionais" (ALVES, BARBOSA, MARTINS, 2008, p. 1). Compreende-se, assim, nas propostas de políticas públicas na educação, marcos de concepções de educação, propostas por determinadas ideias de grupos/organizações de poder. Esses movimentos proporcionaram "manifesta-se o reconhecimento da necessidade de se promover a Educação Infantil tratando a criança como parte da sociedade e a infância como etapa importante no processo de formação humana" (SILVEIRA, BARBOSA, 2018, p. 2).

Os direitos das crianças desde o nascimento passam a ser assegurados. A questão maior será fazer com que sejam de fato materializados. Diz o artigo 227: 
É dever da família, da sociedade e do Estado assegurar à criança, ao adolescente e ao jovem, com absoluta prioridade, o direito à vida, à saúde, à alimentação, à educação, ao lazer, à profissionalização, à cultura, à dignidade, ao respeito, à liberdade e à convivência familiar e comunitária, além de colocá-los a salvo de toda forma de negligência, discriminação, exploração, violência, crueldade e opressão ${ }^{3}$.

Destaca-se o fortalecimento de um novo paradigma sobre a infância brasileira, a partir do qual a criança passou a ser reconhecida como cidadã, e não apenas objeto de tutela, como nas legislações anteriores, que traziam termos como "assistir", "amparar". Inaugurou-se, portanto, o direito das crianças e de suas famílias à educação, e ao Estado o dever de oferecer essa educação. A consolidação desse direito na legislação se dá em processo contraditórios conforme a mobilização dos movimentos sociais havia pressionado. É nessa amplitude de ações que os direitos das crianças vão se constituindo no cenário nacional, internacional, contribuindo para a implementação da Carta Magna de 1988 (ROSEMBERG, s/d).

Os períodos que sucederam a Constituição Federal de 1988 foram marcados pela construção de diversas leis voltadas sobre a Educação Infantil. Em destaque o Estatuto da Criança e do Adolescente (Lei Federal n. 8.069/1990) e a Lei de Diretrizes e Bases da Educação Nacional (Lei Federal n. 9.394/1996), pois essas ressaltam a educação como direito das crianças e o dever do Estado na oferta. Assim como a LDBEN (BRASIL, 1996) reconhece em seu art. 29 a Educação Infantil como primeira etapa da Educação Básica.

Ao longo do processo histórico, houve grandes lutas dos movimentos sociais (Mieib, Anped, Anfope, Anpae) na busca da garantia do que foi propugnado na legislação brasileira e vigilância constante para que a criança tivesse seus direitos garantidos. Podemos observar diferentes ações, como o movimento "Fraldas pintadas", com palavras de ordem "Direito à educação começa no berço e é pra toda a vida" em que o Mieib, juntamente com outras entidades como Campanha Nacional pelo Direito à Educação, Fundação Abrinq, Marcha Mundial de Mulheres, Articulação de Mulheres Brasileiras, Frente Parlamentar da Criança e do Adolescente organizaram ações em que se manifestavam contra a exclusão das matrículas das crianças de zero a três anos de idade na distribuição dos recursos do fundo, sendo que essa exclusão foi à contramão dos princípios constitucionais, dos direitos das crianças brasileiras.

Na década de 2000, com a Lei no 11.494/2007 (BRASIL, 2007), que normatiza sobre o Fundo Nacional de Desenvolvimento da Educação Básica e valorização dos profissionais da Educação (Fundeb) que passa a contemplar 
financiamentos específicos para a Educação Infantil, houve as Emendas Constitucionais n53/2006 e n⿳0 59/2009, cujas materializações implicou numa reconfiguração da Educação Infantil, determinando a mudança dos Anos Iniciais do Ensino Fundamental de oito para nove anos e a instituição de obrigatoriedade de matrícula e frequência na pré-escola. Essas ações evidenciam, pela Câmara Federal e pelo Senado, um desconhecimento das concepções e das práticas pedagógicas da Educação Infantil, e o entendimento equivocado de obrigatoriedade como universalização da oferta.

O que se percebe é que vivemos atualmente o agravamento/intensificação da cisão entre creche e pré-escola, desvalorizando o atendimento da creche, a relação cuidado e educação como elementos indissociáveis, e colocando em relevo que quaisquer pessoas podem realizar esse atendimento, não sendo necessariamente $\mathrm{o} / \mathrm{a}$ professor/a. Importa destacar que a assunção dessa forma de organizar a creche implica na violação da LDB/1996, que determina em seu artigo 62 que para atuar na primeira etapa educacional o profissional deve ser professor habilitado na forma da Lei.

\section{CONSIDERAÇÕES FINAIS}

Analisar a Educação Infantil nos incita a compreender que grandes mudanças marcaram os últimos quarenta anos dessa etapa educacional, como expressa a Legislação Nacional, garantindo os direitos da criança. Hoje, podese dizer que a creche e a pré-escola se constituem numa nova perspectiva, não sem contradições, visto que, de acordo com os documentos legais e as formas de organização dos municípios, essas instituições têm assumido a conotação de um espaço pedagógico, organizado com concepções, funções e objetivos explícitos amplamente divulgados nos documentos elaborados pela Coordenação Geral de Educação Infantil (Coedi). No entanto, há ainda muito por ser feito, pois em sua forma de organização, apesar dos avanços, concepções ligadas à ideia assistencialista relacionada com um viés escolarizante, problemas como a superlotação de crianças na proporção professor/criança, as condições de trabalho e o não cumprimento da exigência de habilitação dos profissionais na forma da Lei exigida para atuar junto às crianças.

Também há iniciativas de privatização na Educação Infantil, em âmbito dos municípios, convênios com instituições privadas que se caracterizam sem fins lucrativos. Essas passam a gerenciar escolas públicas, num viés mercadológico, distanciando a materialização de uma gestão democrática, com participação coletiva de docentes, família, comunidade e as crianças. Ao analisarmos a historicidade das políticas públicas brasileiras para a infância e a educação, explicita-se que a criança 
nem sempre teve direitos assegurados, mas recebeu atendimentos prestados como favor. Dessa forma constaram nas leis e nas ações do Estado a figura do amparo e do assistencialismo, portanto, a criança não era vista como cidadã.

Não podemos deixar de ver a realidade como ela se constitui, como também precisamos deixar viva a esperança, na perspectiva Freiriana. Esperança em uma educação transformadora e potencializadora da construção de um mundo justo e igualitário em que haja a efetivação plena dos direitos, entrelaçando o educar e cuidar como indissociáveis da prática pedagógica, pois são duas dimensões integrantes na prática docente também da própria organização da instituição de Educação Infantil. Essa relação implica na preocupação com o outro em todos os seus aspectos físicos, intelectual, cultural e político. É preciso consciência crítica sobre a realidade para pensar de fato uma educação transformadora que possibilite a efetivação da lei na realidade social.

Desse modo se faz importante colocar a Educação Infantil em pauta na sociedade, na formação de professores, nas instituições educacionais de atendimento das crianças, no intuito de materializar de fato a visão sobre elas. Reconhecendo-a como sujeito de direitos não apenas na legislação, mas nas práticas políticas e sociais, superando a visão assistencialista perdurada por longos anos, de modo que a ela seja garantida em princípios de igualdade, laicidade e pública, com total respeito a diversidade e especificidades dos sujeitos que englobam essa etapa da Educação Básica.

\section{REFERÊNCIAS}

BARBOSA, Ivone Garcia. Infância e educação em direitos humanos. Goiânia: FE/UFG, 2001. Impresso.

BARBOSA, Ivone G.; ALVES, Nancy N. de L.; MARTINS, Telma A. T. Infância e cidadania: ambiguidades e contradições na educação infantil. 31 R. A. Anped. 2008. Disponível em: http://31 reuniao.anped.org.br/1trabalho/GT075024--Int.pdf. Acesso em: 10 de novembro de 2019.

BARBOSA, Ivone Garcia. Das políticas contraditórias de flexibilização e de centralização: reflexões sobre a história e as políticas da Educação Infantil em Goiás. Inter-Ação - Revista da Faculdade de Educação, Goiânia, v. 33, n. 2, p. 379-394, jul./dez. 2008.

BAZÍLIO, Luiz Cavalieri; KRAMER, Sonia (Org.) Infância, educação e direitos humanos. São Paulo: Cortez, 4 ed. 2011. 
BOBBIO, Noberto. A era dos direitos. Rio de janeiro: Elsevier, 2004.

BRASIL. Anais da Assembleia Constituinte. Comissões e Subcomissões. Subcomissão da Educação, Cultura e Esportes. Brasília: Senado Federal. 1987.

BRASIL. Anais da Assembleia Constituinte. Comissões e Subcomissões. Subcomissão da Família, do Menor e do Idoso Brasília: Senado Federal. 1987.

BRASIL. Constituição da República Federativa do Brasil. Brasília: DF, Senado Federal: Centro Gráfico, 1988.

BRASIL. Lei n. 8069, de 13 de julho de 1990. Dispõe sobre o Estatuto da Criança e do Adolescente e dá outras providências. Diário Oficial da União, Brasília, DF, 16 jul. 1990.

BRASIL. Lei n. 9.394 de 20 de dezembro de 1996. (1996). Estabelece as diretrizes e bases da educação nacional. Diário Oficial da União, Brasília-DF.

BRZEZINSKI, Iria. Principios da Carta de GoiÂnia/IVCBE na Constituição Federal "cidadã" (CF/1988): participação da sociedade civil nas políticas educacionais. RBPAE, v. 29, n.2. maio/ago. 2013, p. 223-241.

CAMPOS, Maria Malta. A Constituinte e a educação da criança de 0 a 6 anos. Caderno de Pesquisa, São Paulo, n. 59, p. 57-65 1986.

CAMPOS, Maria Malta. Assistência ao pré-escolar; uma abordagem crítica. Cadernos de Pesquisa, São Paulo, n. 28, p. 53-9, mar. 1979.

CAMPOS, Maria Malta. Uma mulher, uma criança e seus direitos. Cad. Pesqui. 1999, n. 106. Disponível em: https://www.scielo.br/scielo.php?script=sci arttext\&pid $=$ S0100-15741999000100006\&lng=pt\&tlng=pt . Acesso em: 28 abril 2020.

CAMPOS, Rosânia. CAMPOS, Roselane Fátima. A educação das crianças pequenas como estratégia pra o "alivio" da pobreza. Inter-Ação - Revista da Faculdade de Educação, Goiania, V. 33, n. 2, p. 241-263, jul/dez. 2008. 
COELHO, Bernardo Leôncio Moura. A proteção á criança nas constituições brasileiras: 1824-1969. Revista de Informação Legislativa, a. 35, n. 139. Brasília, jul/set 1998.

COMISSÃO DE CRECHE. Creche e Constituinte. s/d. Disponível em: http:/ / www.fcc.org.br/pesquisa/educacaoInfancia/EducacaoInfancia.downloadArtigo. mtw?id=307. Acesso em: 23 abril 2020.

DIDONET, Vital. Balanço crítico da educação pré-escolar nos anos 80 e perspectivas para a década de 90. Em Aberto, Brasília, ano 10, n. 50/51, p. 19-33, abr./set., 1992.

FRIGOTTO, Gaudêncio; CIAVATTA, Maria. Educar o trabalhador cidadão produtivo ou o ser humano emancipado? Trabalho, educação e saúde, Rio de Janeiro, v. 1, n. 1, mar. 2003, p. 45-60.

GALVÃO, Andréia. Marxismo e movimentos sociais. Crítica Marxista, n.32, p. 107-126, 2011.

GOHN, Maria da Glória. 500 anos de lutas sociais no Brasil: movimentos sociais, ONGs e terceiro setor. Revista Mediações, v. 5, n. 1, jan/jun. Londrina, 2000, p. 11-40.

GOMES DA COSTA, Antônio Carlos. É Possível Mudar: a criança, o adolescente e a família na política Social do Município. São Paulo: Malheiros, 1993.

IANNI, Otávio. Teorias da globalização. Rio de Janeiro: Civilização Brasileira, 4 ed. 1997.

MANACORDA, M. A. Marx e a pedagogia moderna. São Paulo: Cortez, 1991.

MARQUEZ, Christine. Garrido. O Banco Mundial e a Educação Infantil no Brasil. Dissertação (Mestrado em Educação) - Faculdade de Educação da Universidade Federal de Goiás, Goiânia, 2006.

MARTINS, Paulo Sena. Carta de Goiânia. Caderno ASLEGIS, Brasília: Câmara dos Deputados, n. 54, $1^{\circ}$ sem. p.141-148, 2018. 
MARX, K. Contribuição à crítica da economia política. São Paulo: Martins Fontes, $2^{\mathrm{a}}$ ed. 1983.

MARX, K.; ENGELS, F. Obras Escolhidas. São Paulo: Alfa-Omega, v. 1. s.d.

OLIVEIRA, Mauro Marcio. Fontes de informações sobre a Assembléia Nacional Constituinte de 1987: quais são, onde buscá-las e como usá-las. Senado Federal Brasília, 1993.

ROSEMBERG, Fúlvia (Org.). Creche. São Paulo. Cortez. 1989.

ROSEMBERG, Fúlvia. Sísifo e a educação infantil brasileira. Pro-posições, v. 14, n. 1, p. 177-194, jan/abr. 2003.

ROSEMBERG, Fúlvia. Crianças e adolescentes na sociedade brasileira e a constituição de 1988. In: OLIVEN. Ruben G.; RIDENTI. Marcelo; BRANDÃO. Gildo M. (Orgs.) A constituição de 1988 na vida brasileira. São Paulo: ANPOCS-HUCITEC, 2008. p. 296-333.

ROSEMBERG, Fúlvia. A criança pequena na agenda de políticas para a infância: representações e tensões. São Paulo, 2010. Disponível em: http:// www.diversidadeducainfantil.org.br/PDF/A\%20CRIAN\%C3\%87 A $\% 20$ PEQUENA\%20NA\%20AGENDA\%20DE\%20POL\%C3\%8DTICAS\%20 PARA $\% 20 \mathrm{~A} \% 20 \mathrm{INF} \% \mathrm{C} 3 \% 82 \mathrm{NCIA} \% 20-\% 20 \mathrm{~F} \% \mathrm{C} 3 \% \mathrm{BAlvia} \% 20$ Rosemberg. pdf . Acesso em: 10 mar. 2020.

ROSSETTI-FERREIRA, M. C. O Apego e as reações da criança à separação da mãe: uma revisão bibliográfica. Cadernos de Pesquisa, n. 48, p. 3-19, fev. 1984

SANFELICE, José Luís. Estado e política Educacional. In: LOMBARDI, José Claudinei (Org.). Temas de pesquisa em educação. São Paulo: Autores Associados/UNC, 2003. p. 162-169.

SILVEIRA, Telma A. Teles M. BARBOSA, Ivone Garcia. A criança de zero a três anos em espaços educativos sob a perspectiva de professoras. In: IV Simpósio Luso-Brasileiro das Crianças e I Encontro das Crianças. 4, Goiânia, 2018. Anais do IV Simpósio Luso-Brasileiro e I Simpósio Luso-Brasileiro das crianças. Goiânia: Mundial gráfica, 2018. 
VIANNA, Luiz Werneck. O terceiro poder na Carta de 1988 e a tradição republicana: mudança e conservação. In: OLIVEN. Ruben G.; RIDENTI. Marcelo; BRANDÃO. Gildo M. (Orgs.) A constituição de 1988 na vida brasileira. São Paulo: ANPOCS-HUCITEC, 2008. p. 91-109.

\section{Priscila Kelida Assis Galvão}

Pedagoga pelo Instituto Federal de Educação, Ciência e Tecnologia de Goiás/ IFG e estudante de especialização em Políticas Educacionais, Gestão Escolar e Trabalho Docente pela Faculdade de Educação/UFG. E-mail: priskelida@gmail. com

\section{Telma Aparecida Teles Martins Silveira}

Pedagoga/UFG, Mestre em Educação/FE-UFG, Doutora em Educação/ FE-UFG. Professora do Instituto Federal de Educação, Ciência e Tecnologia de Goiás/IFG. Membro do Conselho Diretor do Fórum Goiano de Educação Infantil Participante do Núcleo de Estudos e Pesquisas da Infância e sua Educação em Diferentes Contextos - NEPIEC. E-mail: telma.silveira@ifg.edu. br

\section{Ivone Garcia Barbosa}

Graduada em Psicologia/IUP, Mestre em Educação/FE-UFG, Doutora em Educação/FE-USP. Pós-doutora em Estudos da Criança/CIEC-UMINHO. Professora Titular da Faculdade de Educação/UFG. Atua no Programa de Pós-graduação em Educação (mestrado e doutorado). Coordenadora do Núcleo de Estudos e Pesquisas da Infância e sua Educação em Diferentes Contextos (NEPIEC). Presidente do Fórum Goiano de Educação Infantil. ExCoordenadora do GT07 da ANPED. Membro da Diretoria Nacional da Anfope em várias gestões. E-mail: ivonegbarbosa.ufg@gmail.com 